\title{
Comportamiento del sector lechero en el departamento de Boyacá: una aproximación desde la metáfora biológica ${ }^{1}$ Behavior of the dairy sector in the Boyacá department: an approach from the biological metaphor
}

Recibido: 2 de agosto de 2013

Evaluado: 14 de agosto de 2013 Aceptado: 14 de agosto de 2013

\begin{abstract}
Luri Suárez Pineda (Colombia)
Universidad Nacional de Colombia, sede Bogotá

Administradora de Empresas, Universidad Pedagógica y Tecnológica de Colombia; especialista en Proyectos de Desarrollo, Escuela Superior de Administración Pública (ESAP); candidata a Magíster en Administración, Universidad Nacional de Colombia, Bogotá, Colombia.

lurysp@yahoo.com
\end{abstract}

\section{Resumen}

El sector lechero del departamento de Boyacá no está respondiendo adecuadamente a las mutaciones del entorno $y$, en consecuencia, carece de una posición competitiva ventajosa en el mercado. El presente artículo evidencia las razones de esta baja capacidad de respuesta y propone alternativas de solución a partir de la metáfora biológica, toda vez que se convierte en un elemento que hace posible la comprensión del comportamiento de las organizaciones, por lo que una aproximación conceptual desde los comportamientos biológicos

\begin{abstract}
The dairy industry in Boyacá is not responding adequately to changes in the background and, therefore, lacks an advantageous competitive position in the market. This paper highlights the reasons for this low responsiveness and proposes alternative solutions from the biological metaphor, since it is an element that makes possible the understanding of the organizations' behavior, so that a conceptual approach from biological behaviors allows us to propose a model of integration that gambles on improving the
\end{abstract}

1 Artículo de reflexión, Grupo de investigación en Mercadeo, Innovación y Competitividad en Gestión Agropecuaria (Milagro), del área de Metáforas Organizacionales, que hace parte del proyecto de investigación de la Maestría en Administración, Universidad Nacional de Colombia-Convenio UPTC, Duitama (Boyacá). 
permite proponer un modelo de integración que le apuesta a mejorar las capacidades adaptativas del sector lechero de Boyacá, con la pretensión de mejorar su posición competitiva.

Palabras clave: sector lechero, metáfora biológica, integración, competitividad. adaptive capacities of Boyacá dairy sector, with the aim of improving its competitive position.

Keywords: dairy sector, biological metaphor, integration, competitiveness 


\section{Introducción}

En el ámbito mundial, la leche y sus derivados se consideran commodities o bienes básicos (Vera, 2012), se cotizan en dólares y su precio fluctúa en los mercados constantemente (Apymil, 2012). En la búsqueda de mejores precios, la clave está en evolucionar hacia la competitividad, generando diferenciación y valor agregado a los productos, en un entorno de grandes productores y exportadores (Fedegán, 2006).

De conformidad con la Secretaría de Fomento Agropecuario de Boyacá (2011), el sector agropecuario representa $19.2 \%$ del PIB del departamento, en el que la explotación lechera constituye un alto porcentaje, que lo ubica en un tercer lugar de la producción lechera nacional. No obstante, según la Federación Colombiana de Ganaderos (Fedegán, 2012), Boyacá y el resto del país presentan una enorme brecha de productividad que pone al sector en desventaja competitiva frente al resto de naciones, debido a factores que retrasan el proceso de modernización lechera, y que se describen en el presente artículo.

Las implicaciones generadas por los acuerdos de libre comercio agravan la situación, porque la producción nacional tiene que competir en condiciones desfavorables (Castro, 2010). El rápido cambio en el entorno económico internacional demanda de las empresas identificar sus fuerzas y anticiparse a las oportunidades y amenazas a las que se enfrentan, de tal modo que puedan definir sus métodos y prepararse para su implementación, con dirección a garantizar la articulación del proceso internacional con la estrategia global de la empresa (Lemaire, 1997).
Tener claro el panorama del sector lechero ayudará a la construcción de estrategias adecuadas que permitan dar respuestas positivas a las influencias del entorno y a la construcción de ventaja competitiva (Porter, 2010). Encuentra justificación este objeto de estudio, de acuerdo con Aktouf (2004), el saber que, en efecto, todo aumento de la complejidad de un entorno implica para los sistemas que allí se encuentran (incluyendo las organizaciones) la necesidad de aumentar la variedad de sus modos de respuesta frente a los elementos que evolucionan y modifican dicho entorno.

En el propósito de describir cómo son las organizaciones y cómo podrían ser, las metáforas aparecen como ayuda valiosa, ya que a través de ellas es posible estudiar las organizaciones, permitiendo procesos de diagnóstico y evaluación crítica combinados para crear un modo de entendimiento (Morgan, 1998).

El presente artículo describe la situación del sector lechero en Boyacá, permeado por los factores que en el orden nacional explican su nivel competitivo, y mediante la aproximación de la metáfora biológica organizacional se proponen algunas alternativas para solucionar los principales problemas que enfrenta.

\section{Metodología}

Después de hacer una revisión bibliográfica de las metáforas biológicas y concluir que se convierten en elementos que hacen posible la comprensión del comportamiento de las organizaciones, se hizo un acercamiento a los factores que describen la cadena láctea de Boyacá. Una vez hecho este diagnóstico, se desarrolló 
una aproximación conceptual desde los comportamientos biológicos a partir de la metáfora, abordando particularmente el ecosistema coevolutivo organizacional como modelo de gestión de integración empresarial e invocando a Morgan (1998) para retomar que las imágenes generadas por las diferentes metáforas son puntos de referencia idealizados contra los cuales la situación de una organización puede compararse y que la utilidad de la metáfora depende de los propósitos del análisis. En este caso, se aproxima el análisis al ecosistema coevolutivo, a propósito de su uso como alternativa de integración empresarial, que en el presente artículo se ofrece como propuesta para hacer más competitivo el sector lechero, al desarrollar una estrategia que articule la cadena láctea y la integre en sinergia con otras formas de integración de las organizaciones implicadas con el sector.

\section{El sector lechero}

La leche y sus derivados han sido considerados commodities o productos masivos (Vera, 2012). La leche tiene una cotización en dólares en los mercados, y su precio fluctúa al punto que en la década de los noventa llegó a valer menos de
U\$S 1000 la tonelada (Apymil, 2012). En la actualidad la tonelada de leche en polvo entera se ubica en un promedio de 4668 US\$/Ton (Inale, 2013). En la búsqueda de mejores precios para los productos lácteos, tanto los demás países como algunas regiones de Colombia han estado procurando diferenciar y dar valor agregado a algunos de dichos productos. Las posibilidades de nuestro país se limitan un tanto a la colocación de derivados, dada la condición de commodities de la leche en polvo en un mercado mundial de grandes productores y exportadores, dentro de los cuales Colombia ocupa un lugar muy modesto en exportaciones (Fedegán, 2006).

La calidad composicional que caracteriza la producción doble propósito en Colombia constituye un valioso factor de competitividad; no obstante, la brecha resulta ser significativa con los países ganaderos, especialmente en lo que tiene que ver con la calidad higiénica (Fedegán, 2006).

La Fedegán (2012), en el Primer Foro Internacional de la Leche, describió los factores relevantes que retrasan el proceso de modernización lechera colombiana y que aplican para el sector lechero de Boyacá (Gobernación de Boyacá, 2011), los cuales se exponen en el cuadro 1.

Cuadro 1. Principales retos que enfrenta la cadena láctea.

\begin{tabular}{|l|l|}
\hline \multicolumn{1}{|c|}{ Factor } & \multicolumn{1}{c|}{ Descripción } \\
\hline \multirow{2}{*}{$\begin{array}{l}\text { Dispersión a lo largo de todo el } \\
\text { territorio nacional }\end{array}$} & $\begin{array}{l}\text { Gran variedad de condiciones de producción y comercialización de leche, } \\
\text { desde regiones con alto nivel de industrialización y productividad, hasta zo- } \\
\text { nas con bajos niveles de transformación formal pero con alto potencial pro- } \\
\text { ductivo (Fedegán, 2012). Mientras en Colombia existen } 395000 \text { hatos con } \\
\text { una producción de alrededor de } 6300 \text { millones de litros, Argentina reporta } \\
11500 \text { hatos con una producción que sobrepasa los } 11000 \text { millones de li- } \\
\text { tros (Osorio, 2012). Boyacá se caracteriza por ser un departamento de mini- } \\
\text { fundio, que cuenta con } 123 \text { municipios, } 55108 \text { predios y } 766195 \text { bovinos } \\
\text { (Fedegán, 20013c). }\end{array}$ \\
\hline
\end{tabular}


Cuadro 1. Principales retos que enfrenta la cadena láctea. (continuación)

\begin{tabular}{|c|c|}
\hline Factor & Descripción \\
\hline $\begin{array}{l}\text { Baja especialización regional en } \\
\text { actividades de producción lechera }\end{array}$ & $\begin{array}{l}\text { De un inventario nacional de } 2693155 \text { vacas en ordeño, tan solo } 991081 \\
\text { están dedicadas a la explotación en lechería especializada (DANE, 2012). En } \\
\text { el caso de Boyacá, de un inventario de } 249086 \text { vacas en ordeño, solo } 91663 \\
\text { tienen dedicación especializada de producción lechera. }\end{array}$ \\
\hline Reducidas economías de escala* & $\begin{array}{l}\text { En Colombia, donde alrededor de } 70 \text { \% de los productores de leche produ- } \\
\text { cen por debajo de los cien litros diarios, estos se ven enfrentados a un ma- } \\
\text { nejo de altos costos de producción y comercialización, restando posibili- } \\
\text { dades económicas para la adopción de transferencia y tecnología (Baca et } \\
\text { al., 2012). }\end{array}$ \\
\hline $\begin{array}{l}\text { Uso inadecuado, ineficiente y poco } \\
\text { amigable de los recursos naturales }\end{array}$ & $\begin{array}{l}\text { La explotación lechera tiene implicaciones que afectan suelo, agua, aire, } \\
\text { material genético, flora y fauna, recursos que pueden ser degradados por } \\
\text { sobreúso, contaminación, destrucción física y algunos sistemas de produc- } \\
\text { ción (González, 2007). } \\
\text { El escenario de la producción lechera está aliado a los problemas de ero- } \\
\text { sión, acidificación, salinización, compactación, contaminación de los suelos, } \\
\text { extracción neta de sus nutrientes, uso ineficiente de aguas de riego, conta- } \\
\text { minación del agua por agroquímicos y desechos agroindustriales, pérdida } \\
\text { de biodiversidad silvestre, pérdida de masa boscosa, degradación de pastos } \\
\text { por sobrepastoreo y pisoteo, destrucción de los microorganismos del sue- } \\
\text { lo, emisión de metano por ganado y resistencia creciente de las plagas por } \\
\text { el uso reiterado de agroquímicos (González, 2007). }\end{array}$ \\
\hline $\begin{array}{l}\text { Insuficiente prestación de asistencia } \\
\text { técnica y empresarial a los ganaderos }\end{array}$ & $\begin{array}{l}\text { América Latina se caracterizas por contar con una población rural con índi- } \\
\text { ces de educación por debajo de la población urbana (Pérez, 2003). La Secre- } \\
\text { taría de Fomento Agropecuario de la Gobernación de Boyacá (2011), en el } \\
\text { documento Política del sector agropecuario, expone que en el departamento } \\
\text { de Boyacá no hay suficiente coordinación interinstitucional, ni voluntad po- } \\
\text { lítica de los entes locales; existe dificultad en la transferencia de tecnología } \\
\text { de las investigaciones realizadas en la región, incumplimiento de los progra- } \\
\text { mas generales de asistencia técnica, así como de planes de desarrollo y de } \\
\text { ordenamiento territorial. }\end{array}$ \\
\hline $\begin{array}{l}\text { Bajos índices de productividad, baja } \\
\text { eficiencia productiva }\end{array}$ & $\begin{array}{l}\text { América Latina tiene una productividad que apenas llega a la mitad de su } \\
\text { potencial, en la cual factores relacionados con la falta de innovación y polí- } \\
\text { ticas de desarrollo productivo insuficientes o pobremente diseñadas, entre } \\
\text { otras, se convierten en causales del retrasado crecimiento productivo en la } \\
\text { región (Pagés, 2010). } \\
\text { Estadísticas de Fedegán (2013b) y DANE-ENA (2012), reportan que la produc- } \\
\text { tividad de leche en Boyacá comparada con la del resto del mundo es muy } \\
\text { baja, con un registro en litros/vaca/día de 4.1, frente a Estados Unidos con } \\
35.6 \text { y la UE con 21.2. }\end{array}$ \\
\hline $\begin{array}{l}\text { Elevados costos de producción y } \\
\text { deterioro de la rentabilidad }\end{array}$ & $\begin{array}{l}\text { Según expone Osorio (2012), en Colombia el comportamiento de la renta- } \\
\text { bilidad varía de conformidad con la zona de explotación, registrándose su } \\
\text { comportamiento en un rango que se desplaza desde } 4.6 \% \text { apreciado en } \\
\text { hatos de Cundinamarca, hasta } 21.1 \% \text { en Cauca y Nariño. El costo de produc- } \\
\text { ción oscila entre US\$cv/litro } 36.7 \text { y } 43.6 \text {, en tanto que el precio de venta varía } \\
\text { entre US\$cv/litro } 45.4 \text { y 50.3. En el caso del departamento de Boyacá, el sec- } \\
\text { tor lechero ha experimentado una baja de } \$ 200 \text { en el precio de la leche, que } \\
\text { se ha hecho notar de manera importante desde el mes de noviembre de } \\
2012 \text { y que a mayo de } 2013 \text { aún tiende a la baja (Contexto Ganadero, 2013b). }\end{array}$ \\
\hline
\end{tabular}

(continúa)

* El desarrollo de las economías de escala implica la reducción de cada unidad producida dentro de los costos fijos, traduciéndose en una mayor competitividad del producto, específicamente frente a la variable precio (Baca et al., 2012) 
Cuadro 1. Principales retos que enfrenta la cadena láctea. (continuación)

\begin{tabular}{|c|c|}
\hline Factor & Descripción \\
\hline Informalidad & $\begin{array}{l}\text { Débiles estructuras empresariales y vulnerabilidad ante los dinámicos cam- } \\
\text { bios del entorno, que generan nuevas exigencias del mercado a las que no } \\
\text { están en capacidad de responder (Ospina, 2011). } \\
\text { Los altos índices de informalidad protegen a las empresas pequeñas e ineficien- } \\
\text { tes de la competencia de compañías mejores y más productivas (Pagés, 2010). } \\
\text { De conformidad con lo expuesto por el presidente de la Federación de Gana- } \\
\text { deros de Boyacá (Fabegan), la informalidad lechera en el país alcanza } 50 \text { \% de la } \\
\text { producción, cifra a la que no es ajeno el departamento de Boyacá (García, 2013). } \\
\text { Según expone Martínez (2011), no hay compromiso real por parte de las entida- } \\
\text { des gubernamentales para hacer cumplir la ley, sumado a la gran brecha entre el } \\
\text { sector lácteo organizado y el informal, este último fuera de todo control sanitario } \\
\text { y fiscal, lo cual no ofrece garantía alguna de calidad para el consumidor. } \\
\text { Con la expedición del Decreto } 1880 \text { de } 2011 \text { se plantean rigurosas medidas } \\
\text { de control que cobijan a productores y comercializadores de leche cruda, } \\
\text { quienes por ser actores informales, no es fácil identificarlos y nunca han es- } \\
\text { tado sometidos a controles sanitarios o tributarios (Martínez, 2011). }\end{array}$ \\
\hline Insuficiente cultura de calidad** & $\begin{array}{l}\text { Boyacá registra un alto consumo de leche cruda y derivados lácteos producidos } \\
\text { a partir de esta calidad de materia prima, lo que genera graves problemas en el } \\
\text { tema de salud pública, que es preciso mitigar con la intervención de todos los } \\
\text { componentes de la cadena, esto es, desde que se producen las pasturas hasta } \\
\text { cuando el producto llega al consumidor final (Fajardo, 2013). Es preciso tener en } \\
\text { cuenta cada actividad de la empresa, pero también la relación entre ellas y con } \\
\text { las unidades de negocios, de tal modo que permita convertir la complejidad de } \\
\text { la competitividad en una estrategia clara y funcional para el sector (Porter, 2010). }\end{array}$ \\
\hline Sustitución de la explotación lechera & $\begin{array}{l}\text { Resultados de la Encuesta Nacional Agropecuaria (ENA) según el Departa- } \\
\text { mento Nacional de Planeación (DNP, 2012), muestran que el uso del suelo en } \\
\text { los } 22 \text { departamentos del país, corresponde a un área de } 37654254 \text { ha, de } \\
\text { las que } 30000649 \text { están dedicadas a la actividad pecuaria, con una partici- } \\
\text { pación en pastos y forrajes de } 19554514 \text { ha, las cuales tienen una orienta- } \\
\text { ción } 49.6 \% \text { a carne, } 38.5 \% \text { a doble utilidad y } 11.9 \% \text { a leche. Con relación al } \\
\text { año anterior, estas cifras dan muestra de una reducción en el porcentaje de } \\
\text { explotación lechera, como quiera que en } 2011 \text { el dedicado a la explotación } \\
\text { de leche especializada fue } 15.9 \% \text { del total del uso de suelo con participa- } \\
\text { ción en pasturas y forrajes; igualmente, se identifica incremento de la parti- } \\
\text { cipación en doble utilidad, que en } 2011 \text { registró } 36.3 \% \text {; este panorama indi- } \\
\text { ca una reorientación del hato frente a su explotación (DANE, } 2011 \text { ). En } 2011 \text {, } \\
\text { en Colombia, el inventario de cabezas de ganado hembras fue de } 13453 \\
931, \text { de las cuales } 2858779 \text { estuvieron en ordeño, ofreciendo productivi- } \\
\text { dad de } 4.5 \text { Its./vaca/día, para una producción diaria estimada de } 12979075 \\
\text { litros, ocupando Boyacá un privilegiado tercer lugar, como uno de los de- } \\
\text { partamentos de mayor producción lechera en Colombia, con } 290512 \text { vacas } \\
\text { en ordeño que generaron una producción de } 1521994 \text { lts./día, de los cua- } \\
\text { les } 526953 \text { fueron vendidos a la industria, } 595773 \text { a intermediarios y } 399268 \\
\text { dedicados a otros usos (DANE, } 2011 \text { ). Nos encontramos con el mismo esce- } \\
\text { nario de sustitución de la actividad arriba descrito, toda vez que en } 2012 \text { se } \\
\text { redujo el número de hembras a } 12406899 \text { (DANE, } 2012 \text { ). El cuadro } 2 \text { mues- } \\
\text { tra el comportamiento de Boyacá en producción y destino lechero en } 2012 .\end{array}$ \\
\hline
\end{tabular}

* La calidad de la leche corresponde a las características nutricionales dadas por proteína, grasa, lactosa, minerales, vitaminas, sólidos no grasos y sólidos totales, y por las características microbiológicas definidas, como la concentración de bacterias en la leche, presencia de microorganismos patógenos, de residuos antibióticos e inhibidores (Calderón, García y Martínez, 2006). 
Cuadro 2. Destino de la leche producida en Boyacá y su participación en el orden nacional

\begin{tabular}{|l|r|r|r|}
\hline \multicolumn{1}{|c|}{ Producción y venta de leche, litros/día } & \multicolumn{1}{c|}{ Colombia } & \multicolumn{1}{c|}{ Boyacá } & \multicolumn{1}{c|}{ Participación \% } \\
\hline Total litros de leche producida & 12985016 & 1497697 & 11.5 \\
\hline Ventas & 10601204 & 1290842 & 12.2 \\
\hline Industria & 6656984 & 677350 & 10.2 \\
\hline Intermediarios & 3459639 & 585016 & 16.9 \\
\hline Otros & 484581 & 28276 & 10.6 \\
\hline Autoconsumo & 1125858 & 119152 & 7.0 \\
\hline Procesada & 1257954 & 87703 & \\
\hline
\end{tabular}

\section{Características del entorno y sus mutaciones}

Como expone Cunliffe (2008), el sector lechero en nuestra región avizora un futuro de retos, agravado por el incremento en los costos de producción y la presión que generan los acuerdos comerciales internacionales. No obstante, considerando que los costos de los insumos para el sector se mantendrán relativamente altos, Boyacá tiene una ventaja competitiva, pues hace parte de un país tropical que dispone de fuentes seguras de pastos y forrajes con menores costos que los que demandan los suplementos concentrados, situación que se puede aprovechar implementando estrategias en las cuales la organización y administración de las fincas, la aplicación de la ciencia y la técnica, así como la integración en cadenas, sean realmente de provecho para el sector lechero (Ponce, 2009).

Los hatos de nuestra región tienen un tamaño relativamente pequeño, que deja ver una gran brecha cuando los comparamos con los países con los que Colombia ha firmado tratados de libre comercio; no obstante, la ventaja competitiva no está dada por el tamaño del hato, sino por los bajos índices de productividad promedio nacional (Osorio, 2012).

De conformidad con el Ministerio de Comercio, Industria y Turismo (2013), el mercado internacional del sector lechero colombiano se ha reducido en kilos de manera continuada, pasando de 4462 399 en 2010 a 1724502 en 2011 y a 976 976 en 2012.

En Colombia alrededor de 400000 familias dependen de la leche, que en su mayoría tienen producción de subsistencia y pertenecen a las cuencas lecheras de minifundio (Lafaurie, 2013). En 2012 la entrada de leche a Colombia, especialmente de Chile, Argentina y Estados Unidos, fue de 33097 toneladas, observándose $225 \%$ de incremento en las importaciones en relación con 2011, cuando 
se importaron 14724 toneladas (Contexto Ganadero, 2013a).

La importación de lactosueros es otro factor que amenaza el sector lechero colombiano. Según menciona Augusto Beltrán, secretario técnico del Fondo de Estabilización de Precios (FEP), de la Fedegán, en 2013 (citado por Contexto Ganadero, 2013c), durante el periodo comprendido entre enero y abril de 2013 Colombia registró importaciones de 2393 toneladas de lactosuero, lo que representa $15.3 \%$ de incremento en relación con el año anterior, en el que las compras totales fueron de 2076 toneladas, siendo nuestro principal proveedor Chile, con 765 toneladas, seguido de Uruguay y Argentina con 475 y 462 toneladas respectivamente.

\section{La metáfora biológica organizacional}

Illera (1982) sostiene que cada organización constituye una unidad anatómica funcional con características que le permiten evolucionar en el transcurso del tiempo, lo que supone que todo estado presente de una organización es consecuencia de otro que lo antecede y causa de otro que lo procede. En cada organización se puede distinguir una especificidad evolutiva y características propias en lo que respecta a su forma, composición y funciones. Estas características están aseguradas por el sistema de crecimiento, el cual mantiene y regula las modificaciones de la organización que le aseguran su perpetuación.

Analizar la realidad de las organizaciones se ha constituido en tarea de enormes retos y dificultades, toda vez que pretende escudriñar la naturaleza, la estructura y el funcionamiento de las organizaciones como sistemas distintos de las comunidades, las tribus, las etnias, los grupos informales y otras formas de agrupación social (Carrillo, 2003). Frente a este panorama, las formas de análisis metafórico proporcionan recursos que permiten tratar con esta complejidad, a la vez que nos enseñan cómo podemos abrir nuestros procesos de pensamiento de manera que podamos entender la misma situación desde múltiples perspectivas de una forma crítica e informada (Morgan, 1998).

Hablar de metáfora es hablar de innovación, ya que se trata de dar razón de una de las formas expresivas que mayor nivel de criticidad contiene, permitiendo abrirse al futuro y a la necesidad de incidir en la transformación del tiempo presente (Mendoza, 2005).

La metáfora, según el Diccionario de lengua española (2001), es la "aplicación de una palabra o de una expresión a un objeto o a un concepto, al cual no denota literalmente, con el fin de sugerir una comparación (con otro objeto o concepto) y facilitar su comprensión".

La metáfora se constituye en un apareamiento entre dos dominios conceptuales, permitiendo entender y experimentar una cosa en términos de otra, lo que no sugiere entenderla y experimentarla en todos y en los mismos términos de aquella, haciendo posible aparear de manera preferencial los dominios conceptuales que se corresponden en una y otra cosa (Soler, 2004).

En el camino a entender las organizaciones, la metáfora biológica se ha constituido en una metodología aplicada al estudio de la gestión desde el inicio de su 
desarrollo conceptual (Montoya y Montoya, 2012).

Las metáforas son utilizadas siempre que se intenta comprender un elemento de experiencia en términos de otro; permiten entender el complejo y paradójico carácter de la vida organizacional, lo que genera capacidad de diseñar y gestionar organizaciones de un modo que no había sido pensado antes (Morgan, 1998).

Las organizaciones cuentan con un abanico de alternativas biológicas que pueden ser aplicadas a la práctica administrativa, en la búsqueda del fortalecimiento de la integración, dentro de las cuales el enfoque evolutivo, ecosistémico y la sociobiología se convierten en generadores de nuevas metáforas, toda vez que están relacionadas con las funciones de adaptación e interacción de los organismos (Montoya, 2010).

La dependencia de una criatura orgánica a otra descansa generalmente en seres bien remotos en la escala de la naturaleza, lo que ocurre a menudo con criaturas que luchan mutuamente por su existencia, haciéndose más dura entre los individuos de la misma especie, porque frecuentan análogos lugares, viven de idéntico alimento y están expuestos a iguales peligros (Darwin, 1963).

Podría entonces interpretarse la evolución en el escenario empresarial como la capacidad que tiene la organización para adaptarse en mercados altamente competitivos y agresivos (Montoya, 2010).

La coevolución es un cambio evolutivo recíproco dado entre especies interactuantes y conducido por selección natural, lo que explica la decadencia de las especies y la aparición de nuevas, como efecto de un alto grado de coevolución, en el que la especialización recíproca extrema no es una condición necesaria para que las especies puedan interactuar con muchos otros grupos taxonómicos y buena parte de su evolución sea dirigida por las relaciones que establecen con solo una, o unas cuantas, de las demás especies, escenario en el que algunas se vuelven sumamente especializadas para las interacciones, en tanto que otras permanecen o se vuelven menos especializadas (Thompson, 2003).

Las organizaciones suelen adaptarse a las condiciones ambientales en concierto, lo que sugiere un efecto de sistemas, constituyendo sociedades y comunidades, de las que hacen parte organizaciones que se adaptan mediante procesos de ajuste, permeados por las estrategias de desarrollo que orientan sus líderes o gerentes, y que constituyen respuestas que sobrevienen a un escaneo de oportunidades y amenazas, para definir su estructura apropiada (Hannan y Freeman, 1977).

\section{Perfil de las interacciones coevolutivas}

Calvente (2007) expone el perfil característico de las interacciones entre agentes de un sistema complejo, fundamentales en el desarrollo de la diversidad, la innovación, el aprendizaje y la sustentabilidad de cualquier organización compleja, identificadas entre otras como reciprocidad (mutuamente influyentes), aprendizaje (feedback entre agentes), desarrollo estratégico (simbiosis, sinergia, competencia, neutralismo, comensalismo, amensalismo, depredación, parasitismo, invasión, etc.), dinámicas en el espacio y el tiempo (se desarrollan, aumentan, decrecen, desaparecen, vuelven a aparecer), multiescalares (en forma local y en 
diferentes escalas), propagativas y expansivas (ampliación y propagación de las posibilidades de acción), y emergencia (aparición de fenómenos que no se pueden observar en las partes interactuantes en forma aislada).

\section{Ecosistema coevolutivo organizacional como alternativa para mejorar la competitividad del sector lechero de Boyacá}

El concepto de ecología organizacional fue acuñado para capturar el hecho de que todas las organizaciones constituyen un sistema ecológico esencialmente complejo, caracterizado por la interdependencia de sus actores, en el que un cambio en cualquiera de sus aspectos repercutirá en todo el sistema (Becker, 2007). En este orden de ideas, la organización y la industria se comportan como un ecosistema por su interrelación con otros organismos e instituciones, compitiendo por recursos escasos y con la necesidad de alcanzar los objetivos estratégicos propuestos (Montoya, 2010). La alternativa de ecosistema encuentra aplicación para el sector lechero de Boyacá, invocando a Montoya (2010), amén de su aplicabilidad en los sectores agroindustriales, especialmente por la vinculación entre los diferentes actores que componen el sector y su disposición a implementar sistemas de integración empresarial. En consecuencia, la propuesta se constituye en un ecosistema coevolutivo organizacional, que permita fortalecer la cadena láctea y articularla e integrarla con otras formas asociativas, para responder a las exigencias competitivas del mercado.

\section{La cadena láctea: un} ecosistema coevolutivo como propuesta para el

El legislativo colombiano, por medio de la Ley 811 de 2003, referida a las organizaciones de cadenas en el sector agropecuario, entiende por cadena productiva el conjunto de actividades que se articulan técnica y económicamente, desde el inicio de la producción y elaboración de un producto agropecuario, hasta su comercialización final, conformada por todos los agentes que participan en la producción, transformación, comercialización y distribución de un producto agropecuario.

El uso de las cadenas agroalimentarias como instrumentos de competitividad y de política ayuda a consolidar la institucionalidad del sector agrícola y rural (García et al., 2009).

Mediante la Ley 101 de 1993, modificada por la Ley 811 de 2003, se crean las organizaciones de cadenas en Colombia, entre otras, la del sector agropecuario.

Por medio de la Resolución 76 del 7 de julio de 1999, del Ministerio de Agricultura y Desarrollo Rural (MADR), fue creado el Consejo Nacional Lácteo (CNL), reconocido a través de la Resolución 82 del 24 de marzo de 2011, expedida por el MADR, como la organización de la cadena del sector lácteo colombiano. Dicha Ley 811 reza que los integrantes de una organización de cadena ponen a disposición de esta sus organizaciones y 
sus estrategias, que en lugar de confrontarse se coordinan, con el fin de obtener un mejor desempeño económico, a su vez colectivo e individual. Su misión se origina en una libre decisión de sus actores de aliarse para mejorar su competitividad, a partir de un análisis del mercado, y de su disposición para adecuarse a las necesidades de los integrantes de la cadena $(\mathrm{CNL}$, 1999). Con similares propósitos, en el departamento de Boyacá, el 13 de marzo de 2006 se conformó el Consejo Departamental de la Cadena Láctea (Dehaquiz, 2008).

El cuadro 3 muestra el diagnóstico situacional de la cadena láctea de Boyacá, resultado de la investigación realizada por Dehaquiz (2008), y que da cuenta de las fortalezas y debilidades de los eslabones que la constituyen.

Cuadro 3. Análisis estratégico del perfil de los diferentes eslabones

de la cadena láctea en el corredor industrial de Boyacá.

\begin{tabular}{|c|c|c|}
\hline Eslabón & Fortalezas & Debilidades \\
\hline Hato lechero & $\begin{array}{l}\text { Mejoramiento y rotación de praderas. Mejoramien- } \\
\text { to genético con razas especializadas. Procesamien- } \\
\text { to y conservación de forrajes en algunos hatos. }\end{array}$ & $\begin{array}{l}\text { Baja capacitación para los trabajadores } \\
\text { de la finca. Terrenos muy pequeños, mi- } \\
\text { cro y minifundio, que hace que no sea } \\
\text { rentable la actividad. Poco acceso a ma- } \\
\text { terias primas e insumos. En los hatos } \\
\text { más pequeños se adolece de sanidad } \\
\text { preventiva. }\end{array}$ \\
\hline Ordeño & $\begin{array}{l}\text { Buenas prácticas de manejo en la mayoría de los ha- } \\
\text { tos medianos y grandes (entre diez y cien vacas en } \\
\text { ordeño). Estos hatos cuentan con ordeños mecáni- } \\
\text { cos y procesos puntuales en la realización de esta } \\
\text { actividad. }\end{array}$ & $\begin{array}{l}\text { Falta de capacitación para la realización } \\
\text { del ordeño. Higiene en el ordeño muy } \\
\text { baja. En los pequeños hatos (menos de } \\
\text { diez vacas en ordeño) no se cuenta con } \\
\text { ordeñadora mecánica, esto hace que las } \\
\text { procesadoras de leches como Parmalat, } \\
\text { Alpina, entre otras, no compren estas le- } \\
\text { ches, las cuales van a venta directa de } \\
\text { leches crudas y a procesadoras micro o } \\
\text { pequeñas. }\end{array}$ \\
\hline $\begin{array}{l}\text { Transporte de leche } \\
\text { cruda }\end{array}$ & $\begin{array}{l}\text { El corredor industrial presenta las mejores vías del } \\
\text { departamento. Algunas empresas ya cuentan con } \\
\text { transporte especializado. }\end{array}$ & $\begin{array}{l}\text { En algunas veredas con vocación leche- } \\
\text { ra la distancia hace que no se recoja el } \\
\text { producto en transporte especializado. } \\
\text { Todavía se transporta la leche de mane- } \\
\text { ra artesanal, en áreas del corredor indus- } \\
\text { trial. Algunos comerciantes en transpor- } \\
\text { te de leche cruda no están capacitados } \\
\text { en buenas prácticas de manipulación } \\
\text { (BPM) de este producto, implicando pro- } \\
\text { blemas de salud pública. }\end{array}$ \\
\hline $\begin{array}{l}\text { Industria procesadora } \\
\text { de lácteos }\end{array}$ & $\begin{array}{l}\text { Algunas empresas están abiertas al cambio y a im- } \\
\text { plementar BPM; las que aún no las tienen, ISO } 9000 \\
\text { e ISO 14000. La tecnología empleada es buena, en } \\
\text { algunas agroindustrias hay subutilización de equi- } \\
\text { pos. }\end{array}$ & $\begin{array}{l}\text { La gerencia no ha tenido en cuenta ca- } \\
\text { pacitaciones a su personal. Como toda- } \\
\text { vía no están implementadas normas de } \\
\text { calidad y medio ambiente, no hay acce- } \\
\text { so a mercados especializados }\end{array}$ \\
\hline
\end{tabular}


Cuadro 3. Análisis estratégico del perfil de los diferentes eslabones de la cadena láctea en el corredor industrial de Boyacá. (continuación)

\begin{tabular}{|l|l|l|}
\hline \multicolumn{1}{|c|}{ Eslabón } & \multicolumn{1}{|c|}{ Fortalezas } & \multicolumn{1}{c|}{ Debilidades } \\
\hline $\begin{array}{l}\text { Transporte del } \\
\text { producto procesado }\end{array}$ & $\begin{array}{l}\text { La mayoría de empresas poseen transporte especia- } \\
\text { lizado para la distribución de sus productos. Los co- } \\
\text { mercializadores, en muchas ocasiones, recogen el } \\
\text { producto en planta. }\end{array}$ & $\begin{array}{l}\text { No siempre se guardan en una buena } \\
\text { tan pérdidas significativas por mal ma- } \\
\text { nejo de los productos en el transporte. }\end{array}$ \\
\hline Mercadeo & $\begin{array}{l}\text { Hay amplios canales de comercialización (locales, } \\
\text { regionales, nacionales). }\end{array}$ & $\begin{array}{l}\text { No es una zona libre de fiebre aftosa. No } \\
\text { se hadido incursionar en mercados } \\
\text { especializados por la falta de normatiza- } \\
\text { ción en plantas. }\end{array}$ \\
\hline Consumo & $\begin{array}{l}\text { Cada día aumentan los consumidores de productos } \\
\text { derivados de la leche. La leche es el producto por } \\
\text { excelencia para la alimentación y nutrición humana, } \\
\text { especialmente la de niños en edad preescolar, prea- } \\
\text { dolescentes y adolescentes. }\end{array}$ & $\begin{array}{l}\text { Se requiere una concientización de los } \\
\text { consumidores de leches para que to- } \\
\text { men cultura de consumir leches } \\
\text { procesadas y así evitar enfermedades } \\
\text { zoonóticas (brucellosis, entre muchas } \\
\text { otras) y no zoonóticas en el organismo } \\
\text { humano (obstrucción arterial). }\end{array}$ \\
\hline
\end{tabular}

Fuente: Dehaquiz (2008).

La Fedegán (2013a) expone en su plan quinquenal 2013-2018 como objetivos para mejorar la competitividad del sector lechero en Colombia, el manejo estratégico de variables claves que tienen que ver con productividad, sostenibilidad, empresarización, asociatividad y encadenamiento, unidas a un accionar directo de integración regional que involucre la industria y la academia para satisfacer la demanda de formación, investigación y extensión; al Gobierno en la fijación de políticas y el aporte de recursos; a los ganaderos con capacidad en la toma de decisiones empresariales y a los gremios.

Teniendo en cuenta el panorama descrito, se hace necesario que el sector lechero de Boyacá trabaje como un ecosistema capaz de articular la cadena láctea con instituciones gubernamentales, organizaciones gremiales, academia, organismos financieros y sectores conexos, en los que los propósitos sobrepasen los intereses de las partes y se privilegie el desarrollo del territorio, que en consecuencia significa, además de la resolución de los problemas que comparten, un aporte al desarrollo local, y es de esta naturaleza la expectativa del territorio de Boyacá sobre el sector lácteo.

La búsqueda de nuevos enfoques que propendan por la innovación y el crecimiento y redunde en mayores beneficios para la sociedad parte de tres formas claves para que las empresas hallen oportunidades de crear valor compartido: reconcebir los productos y mercados, redefinir la productividad en la cadena de valor y permitir el desarrollo de asociatividad local (Porter y Kramer, 2011). La propuesta que se presenta en la figura 1 converge con la adaptación e interacción de los 
organismos que en la metáfora biológica el enfoque evolutivo ecosistémico consagra, y da la razón a Thompson (2003) cuando afirma que buena parte de la evolución de las especies es dirigida por las relaciones que establecen con otras.

Figura 1. Propuesta ecosistémica para el sector lechero de Boyacá.
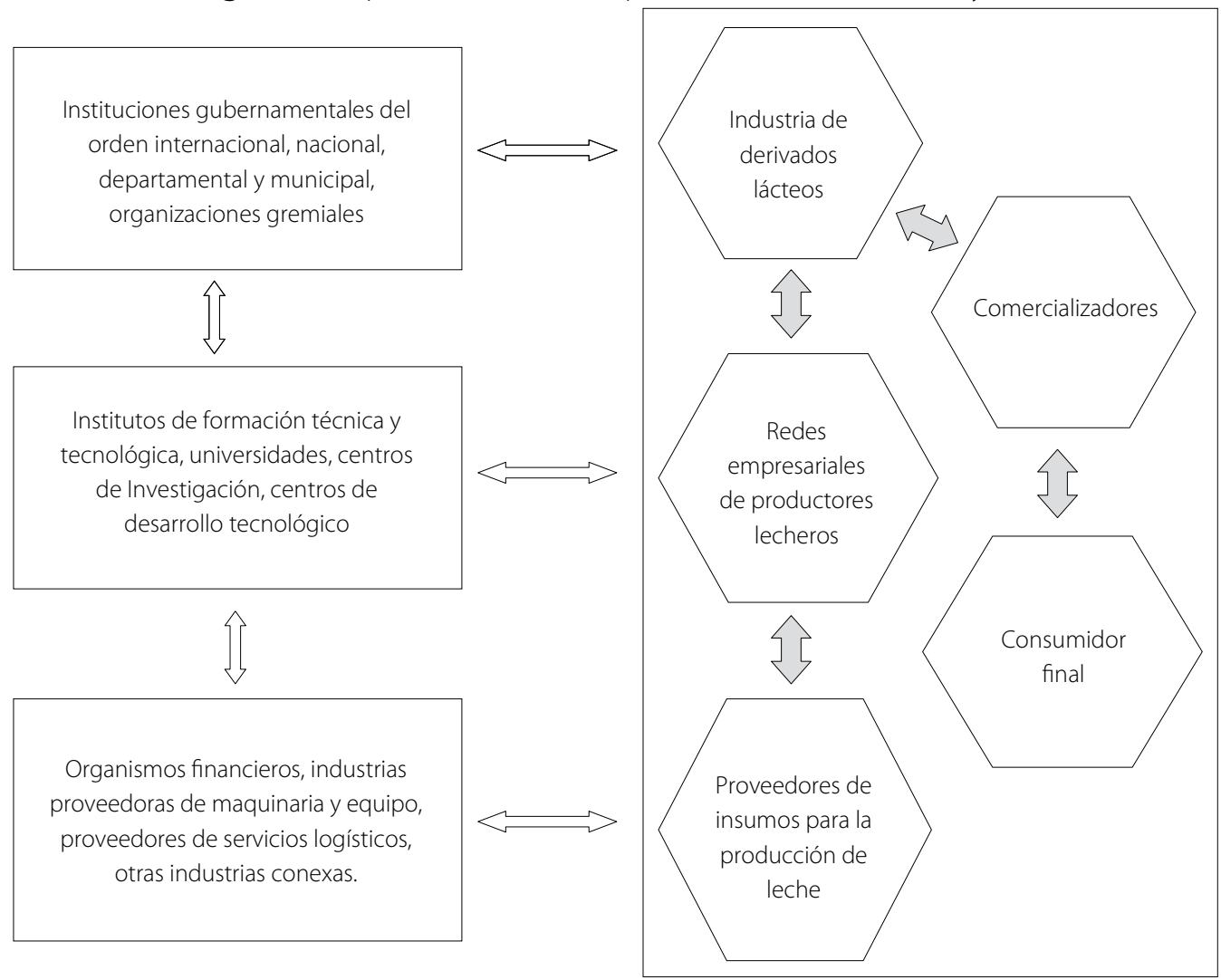

Tomado de Molano et al. (2009).

\section{Conclusiones}

Se evidencia que la explotación lechera en el departamento de Boyacá se caracteriza a partir de factores permeados por el comportamiento del sector lácteo en el orden nacional, haciéndose notoria la dificultad de mantener competitividad en el mercado global.
Se pudo identificar que los eslabones que conforman la cadena láctea se encuentran desarticulados, evidenciándose el trabajo individual, especialmente en el eslabón primario de la cadena.

Frente a los propósitos de competitivi$\mathrm{dad}$, no es notoria la existencia en la región de integración empresarial que permita un trabajo colaborativo, capaz de 
mitigar los factores que encrudecen el desarrollo del sector lácteo.

Los sectores conexos y de apoyo tales como instituciones gubernamentales, organizaciones gremiales, academia, organismos financieros y de servicios, dan muestra de interés colaborativo a partir de normatividad, sin que en la práctica pueda mostrarse un compromiso real alrededor de apuestas concertadas con la cadena láctea.

Analizado el sector lechero de Boyacá desde la mirada de la metáfora biológica, que hace posible el estudio de las organizaciones y la comprensión de su comportamiento, y para este caso desde el ecosistema coevolutivo como alternativa biológica, en la búsqueda del fortalecimiento de la integración de las comunidades que conforman el sector, se concluye que efectivamente demandan una absoluta complementariedad, toda vez que los productos de unas se convierten en los insumos de las otras y juntas elevan su capacidad de competitividad que de manera individual las amenaza.

Queda claro que la competitividad perseguida por el sector lechero de Boyacá es posible en una actuación de correspondencia mutua, que se muestra entorpecida por las partes de ese conjunto que no actúa en cooperación, y en consecuencia, influyen en lo que en aproximación a la metáfora biológica se constituye en el ecosistema del sector lechero, lo que permite corroborar que el todo es más que la suma de sus partes.

Un ecosistema encuentra en la práctica la conformación de modelos asociativos que permiten integrar la cadena láctea, las redes empresariales y los sectores conexos y de apoyo, lo que podría permitir mejores niveles de competitividad para el sector, capaces de jalonar el desarrollo regional.

\section{Referencias}

I. Aktouf, O. (2004). La estrategia del avestruz: posglobalización, management y racionalidad económica. Cali, Colombia: Artes Gráficas del Valle Editores.

2. Apymil (2012). La leche ies un commodities? Consultado el 24 de junio de 2013, Obtenido de http://www.pymeslacteas.com.ar/articulos.php?id=1789\#

3. Baca, J.; Mendoza, B.; Sánchez, M.; Suárez, V.; Volpe, I. y Altamiranda, L. (julio 23-27 de 2012). Tenth LACCEI Latin American and Caribbean Conference for Engineering and Technology (LACCEI' 2012). Desarrollo y competitividad, clave fundamental del sector lácteo colombiano. Consultado el 24 de junio de 2013. Obtenido de http:// www.laccei.org/LACCEI2012-Panama/ RefereedPapers/RP255.pdf

4. Becker, F. (2007). Organizational Ecology and Knowledge Networks. Obtenido el 16 de julio de 2013, de http://iwsp.human. cornell.edu/file_uploads/OrgEcologyandKnowledgeNetworks_1250007926.pdf

5. Calderón, A.; García, F. y Martínez, G. (2006). Indicadores de calidad de leches crudas en diferentes regiones de Colombia. Obtenido el 4 de julio de 2013, de http://www.scielo.unal.edu.co/scielo. php?script=sci_arttext\&pid=S012202682006000100006\&lng=es\&nrm =iso

6. Calvente, A. (2007). Coevolución: un proceso central para la sustentabilidad. Obtenido el 16 de julio de 2013, de http://www.sustentabilidad.uai.edu. 
ar/pdf/cs/uais-cs-200-005\%20-\%20 coevolucion.pdf

7. Carrillo, J. (2003). Analogía y metáfora en el análisis organizacional. Un ejemplo: la organización como cárcel. Revista Colombiana de Psicología, 12,108113.

8. Castro, G. (2010). Sector poco competitivo. Infortambo Andina, 25, 16-18.

9. Colombia, Congreso de la República (2003). Ley 811 de 2003. Bogotá, Colombia: Diario Oficial.

io. Colombia, Departamento Administrativo Nacional de Estadística, DANE (2011). Encuesta Nacional Agropecuaria, ENA. Obtenido el 22 de junio de 2013, de http://www.dane.gov.co/files/ investigaciones/agropecuario/ena/boletin_ena_2011.pdf

I I. Colombia, Departamento Administrativo Nacional de Estadística, DANE (2012). Encuesta Nacional agropecuaria, ENA. Obtenido el 22 de junio de 2013, de http://www.dane.gov.co/files/ investigaciones/agropecuario/ena/presentacion_Boyaca_2012.pdf

I2. Colombia, Federación Colombiana de Ganaderos, Fedegán (2012). Pri mer Foro Internacional de la Leche. Obtenido el 22 de junio de 2013, de http://portal.fedegán.org.co/portal/page?_pageid $=93,92124382 \&$ _ dad=portal\&_schema=PORTAL

I3. Colombia, Federación Colombiana de Ganaderos, Fedegán (2013a). Plan Quinquenal 2013-2018. Bogotá, Colombia: Fedegán.

I4. Colombia, Federación Colombiana de Ganaderos, Fedegán (2013b). Proyecciones de la ganadería colombiana. Bogotá, Colombia: Fedegán.

I 5. Colombia, Federación Colombiana de Ganaderos, Fedegán (2013c).
SIT-Fedegán. Vacunación fiebre aftosa II Ciclo 2012. Bogotá, Colombia: Fedegán.

I6. Colombia, Gobernación de Boyacá Secretaría de Fomento Agropecuario (2011). Política del sector agropecuario, departamento de Boyacá. Obtenido el 2 de julio de 2013, de http://prooofffpdf. files.wordpress.com/ 2011/11/boyaca diagnostico.pdf

I7. Colombia, Ministerio de Agricultura y Desarrollo Rural, MADR (2011). Resolución 82 del 24 de marzo de 2011. Bogotá, Colombia: MADR.

I8. Colombia. Ministerio de Agricultura y Desarrollo Rural, MADR (2012). Unidad de seguimiento de precios de la leche, MADR. Obtenido el 22 de junio de 2013, de http://portal.fedegán. org.co/pls/portal/docs/PAGE/PORTAL/ ESTADISTICAS1/PRODUCCION/COYUNTURA_LACTEA/ BOLETIN\%20COYUNTURA\%20 SECTOR\%20LACTEO \%20-\%20 USP\%20-\%20JULIO\%202012.PDF

I9. Colombia. Ministerio de Comercio, Industria y Turismo (2013). Exportaciones colombianas de producto(s) por sectores agroindustriales. Obtenido el 14 de junio de 2013, de https://www.mincomercio.gov.co/mincomercioexterior/index.php

20. Consejo Nacional Lácteo, CNL (1999). Estatutos de la organización de la cadena láctea colombiana. Obtenido el 18 de julio de 2013, de http://www.cnl.org. co/index.php?option=com_remository \&Itemid $=\&$ func $=$ startdown\&id $=880$

21. Contexto Ganadero (2013a). Chile y Argentina, paises que más venden leche a Colombia. Obtenido el 3 de julio de 2013, de http://www.contextoganadero. com/economia/chile-y-argentinapaises-que-mas-venden-leche-colombia 
22. Contexto Ganadero (2013b). En Boyacá se desploma precio de la leche pagado al productor. Obtenido el 2 de julio de 2013, de http://contextoganadero.com/ regiones/en-boyaca-se-desploma-precio-dela-leche-pagado-al-productor.

23. Contexto Ganadero (2013c). Estudian medidas para mitigar importaciones de lácteos. Obtenido el 3 de julio de 2013, de http://contextoganadero.com// economia/estudian-medidas-para-mitigarimportaciones-de-lacteos

24. Cunliffe, D. (2008). ¿Sabe usted cuánto cuesta producir un litro de leche? Obtenido el 29 de junio de 2013, de http://dcunliffe.perulactea. com/ 2008/07/14/\%C2\%BFsabe-usted-cuanto-le-cuesta-producir-un-litrode-leche/

25. Darwin, C. (1963). El origen de las especies por la selección natural. España: Ediciones Ibéricas.

26. David, F. (2008). Conceptos de administración estratégica. México: Pearson Educación.

27. Dehaquiz, J. (2008). Modelo de gestión ambiental para las pequeñas empresas lácteas del corredor industrial de Boyacá. Bogotá, Colombia: Universidad Nacional de Colombia.

28. Departamento Nacional de Planeación, DNP (2006). Visión Colombia, Segundo Centenario: 2019 (pp. 149). Bogotá, Colombia: Departamento Nacional de Planeación.

29. Federación Nacional de Ganaderos, Fedegán (2006). Plan estratégico de la ganadería colombiana 2019. Bogotá, Colombia: Sanmartín Obregón.

30. García, S. (2013). La leche no escapa a la informalidad, alarmantes cifras afectan al sector. Obtenido el 23 de junio de 3013, de http://www. contextoganadero. com/reportaje/ la-leche-no-escapa-la-informalidadalarmantes-cifras-afectan-al-sector

3 I. García, M.; Riveros, H.; Pavez, I.; Rodríguez, D.; Lam, F.; Arias, J. y Herrera, D. (2009). Cadenas agroalimentarias: un instrumento para fortalecer la institucionalidad del sector agricola y rural. Obtenido el 18 de julio de 2013, de http://unpan1.un.org/intradoc/groups/ public/documents/icap/ unpan045135. pdf

32. González, F. (2007). El avance de la agricultura sostenible en América Latina. Obtenido el 24 de junio de 2013, de http://fgonzalesh.blogspot. com/2007/03/el-avance-de-la-agricultura-sostenible.html

33. Hannan, M. y Freeman, J. (1977). The Population Ecology of Organizations. American Journal of Sociology, 82(5), 929-964.

34. Illera, L. (1982). Anatomía y fisiología de la organización. Bogotá, Colombia: Universidad de La Salle.

35. Inale (junio de 2013). Licitación $N^{o}$. 2. Obtenido el 14 de junio de 2013, de http://www.inale.org/ innovaportal/v/2483/1/innova.front/ licitacion_no_2_junio_2013.html

36. Lafaurie, J. (primer semestre de 2013). Apartes de la presentación del documento "Proyecto de ley para la reconversión del sector lácteo". Cuadernos Ganaderos Fedegán - FNG, 8, 55.

37. Lemaire, J. (1997). Stratégies d'internationalisation. París, Francia: Dunod.

38. Martínez, J. (20 de junio de 2011). Plantean estrictas medidas de control a productores y comercializadores, difíciles de identificar. Portafolio.

39. Mendoza, V. (2005). Metáfora: racionalidad comunicativa y responsabilidad ética. Razón y Palabra, 8(35), 1-10. 
40. Molano, E.; Suárez, M. y Briceño, N. (2009). Análisis de competitividad internacional del sector lácteo en el departamento de Boyacá. Bucaramanga, Colombia: Instituto Tecnológico de Estudios Superiores de Monterrey.

4I. Montoya, L. y Montoya, I. (2012). Metáforas biológicas aplicadas a las organizaciones. Bogotá, Colombia: Universidad Nacional de Colombia.

42. Montoya, L. (2010). Gestión de sistemas de integración empresarial desde una perspectiva biológica. Bogotá, Colombia: Universidad Nacional de Colombia.

43. Morgan, G. (1998). Imágenes de la organización. México: Alfaomega.

44. Osorio, F. (2012). Competitividad de las cuencas lecheras especializadas en Colombia. Notas lecheras. FINCA.

45. Ospina, O. (2011). Análisis de las principales caracteristicas de las empresas en Antioquia. Obtenido el 24 de junio de 2013, de http://www.camaramedellin. com.co/site/Portals/0/Documentos/ Biblioteca/raed-Numero-2-dfhfgh.pdf 46. Pagés, C. (2010). La era de la productividad. Cómo transformar las economias desde sus cimientos. Obtenido el 28 de junio de 2013, de http:// www.iadb.org/research/dia/2010/files/ dia_2010_spanish.pdf

47. Panamá, Latin American and Caribbean Conference for Engineering and Technology LACCEI. (2012). Desarrollo y competitividad, clave fundamental del sector lácteo colombiano. Obtenido el 19 de junio de 2013, de www.laccei.org/LACCEI2012-Panama/ReferendPapers/RP255.pdf

48. Pérez, G. (2003). Formación de capital humano rural y su papel en el crecimiento del sector agropecuario. Educación y competitividad. Obtenido el 26 de junio de 2013, de http://www.eclac. org/publicaciones/xml/6/14316/Capitulo6.pdf

49. Ponce, P. (2009). Un enfoque crítico de la lechería internacional y cubana. Salud Animal, 31(2), 77-85.

50. Porter, M. y Kramer, M. (2011). La creación de valor compartido. Obtenido el 5 de julio de 2013, de http:// www.filantropiatransformadora.org/ attachments/article/198/Shared\%20 Value\%20in\%20Spanish.pdf

5I. Porter, M. (2010). Ventaja competitiva. Creación y sostenibilidad de un rendimiento superior. España: Pirámide.

52. Real Academia Española (2001). Diccionario de la lengua española (vigésima segunda ed.). Obtenido el 15 de julio de 2013, de http://lema.rae.es/drae/ ?val=metafor

53. Soler, S. (2004). Discurso y género en historias de vida. Bogotá, Colombia: Instituto Caro y Cuervo.

54. Thompson, J. (2003). El proceso evolutivo. México: Fondo de Cultura Económica.

55. Vera, R. (2012). Carne y leche: commodities, productos diferenciados y pasturas. Obtenido el 24 de junio de 2013, de http://www.pasturasdeamerica. com/ articulos-interes/notas-tecnicas/ carne-leche-commodities-productosdiferenciados-pasturas/ 